\title{
OCORRENCIA DE SEDIMENTOS MESOCRETÁCEOS TIPICAMENTE MARINHOS NO ESTADO DE ALAGOAS
}

\author{
GERALDO DA COSTA BARROS MUNIZ*, FLAVIO ROCHA** \\ Q LUZINETE VICENTE DE OLIVEIRA RAMIRES
}

\begin{abstract}
In this work, typical middle cretaceous sediments in the Alagoas graben, State of Alagoas, belonging to the so called Sergipe-Alagoas basin, are mentioned for the first time. These sediments are silicified limestones containing cephalopods and indeterminable turritellid gastropods and bivalvia. The presence of the cephalopod genera Acanthohoplites and Lyelliceras also noted for the first time in Brazil permit one to give a probable Early Albian age to the respective sediments. Everything indicates a time correlation between these sediments and those of the Riachuelo Formation of the State of Sergipe. It is also very probable that both sediments are of the same formation, although silicified in Alagoan territory.
\end{abstract}

INTRODUÇÃo Numerosos e notórios estudos realizados na bacia Sergipe-Alagoas, em sua quase totalidade devidos ao Conselho Nacional de Petróleo e à Petrobrás, não consignaram até agora, segundo a bibliografia de que dispusemos, afloramentos de sedimentos cretáceos inquestionavelmente marinhos em território alagoano. Em subsuperfície, no entanto, sabe-se que a Formação Calumbi, porção superior do Grupo Cotinguiba, cuja idade oscila do Campaniano ao Eoceno Inferior, ocorre em território alagoano.

Em relação à bacia Sergipe-Alagoas, a paleofauna cretácea indicadora de ambiente marinho tem sido descrita, reexaminada ou simplesmente mencionada por vários paleontólogos, todos eles referindo os respectivos materiais ao denominado graben de Sergipe. Dentre os fósseis em tais condições são assinalados diversos cefalópodes entre os quais se destacam os gêneros Oxytropidoceras, Douvilleiceras, Mortoniceras, Puzosia e Neokentroceras; moluscos bivalves, como Trigonia e Inoceramus; gastrópodes, como Tylostoma, além de equinóides, foraminíferos e corais. Isto para exemplificarmos apenas o documentário Aptiano-Albiano, correspondente à Formação Riachuelo.

Mendes e Petri (1971) são os únicos autores a mencionar a presença de braquiópodes na Formação Maceió, privativa do denominado graben de Alagoas. Essa referência se deve certamente a uma falha datilográfica nos manuscritos ou mesmo de natureza tipográfica na notável síntese sobre a Geologia do Brasil realizada pelos mesmos. A denominação braquiópode foi grafada em lugar de branquiópode. 'Como se sabe, este último grupo está bem representado sobretudo em folhelhos da Formação Maceió.

Localização dos afloramentos Os sedimentos, que na parte observada parecem conter uma reduzida macrofauna, foram constatados pelos dois primeiros autores deste trabalho na propriedade Tapera, à margem esquerda do Rio Sumaúma, no município de Marechal Deodoro. Este município situa-se aproximadamente a sudoeste da capital alagoana, distando a referida propriedade cerca de $66 \mathrm{~km}$ de Maceió, por rodovia. O Rio Sumaúma deságua na Lagoa Manguaba.

A extensão superficial do afloramento até agora observado é de ordem de $1,5 \mathrm{~km} \times$ $\times 50 \mathrm{~m}$. Segundo informações de moradores da região, os mesmos tipos de rochas ocorrem em propriedades vizinhas. É pouco provável que a sedimentação em apreço tenha caráter restrito à amplitude até agora constatada.

*Instituto de Geociências da Universidade Federal de Pernambuco, com ajuda do Conselho Nacional de Desenvolvimento Científico e Tecnologico (CNPq)

**Instituto de Geociências da Universidade Federal de Alagoas 
Litologia Os sedimentos que são de natureza silicosa, os quais denominaremos cherts (s.l.), apresentam-se às vezes de forma compacta, mas em sua grande maioria se constituem de nódulos, cilindros e de outros tipos morfológicos muito comuns aos cherts. Tais dispositivos de morfologia variada estão imersos em uma matriz dominantemente argilosa, provinda provavelmente da decalcificação parcial do calcário original.

Em muitos casos, pode-se observar no chert a preservação da estrutura oolítica originalmente calcária.

Os macrofósseis observados se encontram silicificados nas mesmas condições da matriz.

São bem conhecidas na região em lide as ocorrências de diatomáceas. Tais algas silicosas, que muito se desenvolveram a partir do Cretáceo Superior, devem ser, com pouca dúvida, as responsáveis pela substituiçăo total do conjunto calcário.

Os macrofósseis encontrados Face à natureza identicamente silicosa da matriz, os raros fósseis encontrados até agora são de difícil observação. $O$ documentário se constitui de alguns gastrópodes e moluscos bivalves, fragmentários em ambos os casos, uma porção de molde externo de um dos flancos de um cefalópode e finalmente outro fragmento também de cefalópode onde ainda podem ser observados vestígios da concha substituída.

Os gastrópodes parecem todos pertencer a uma mesma espécie da família Turritellidae, cujo gênero não pode ser diagnosticado com segurança em virtude de não se encontrarem preservados detalhes, entre os quais as linhas de crescimento, modernamente consideradas fundamentais na distinção genérica dentro daquela família. Os escassos Bivalvia, além da fragmentação, não possuem a charneira conservada.

Quanto aos cefalópodes, um acurado estudo das porções fragmentárias nos permitiu determinações genéricas depois de obtidos moldes em plastilina e gesso.

$$
\begin{aligned}
\text { Filo } & \text { MOLLUSGA } \\
\text { Classe } & \text { Cephalopoda } \\
\text { Ordem } & \text { Ammonoidea } \\
\text { Subordem } & \text { Ammonitina } \\
\text { Superfamília } & \text { Hoplitaceae } \\
\text { Família } & \text { Douvilleiceratidae } \\
\text { Subfamília } & \text { Acanthohoplitinae } \\
\text { Gênero } & \text { Acanthohoplites Sinzow, } 1907 \\
& \text { Acanthohoplites sp. }
\end{aligned}
$$

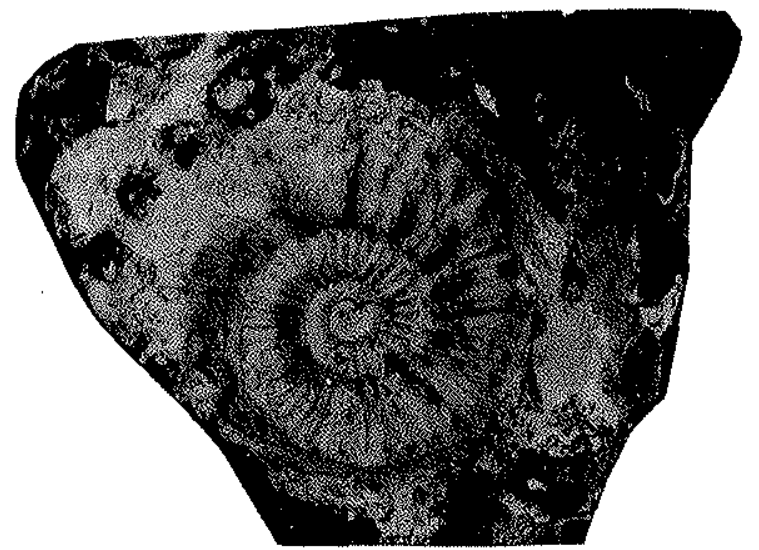

Figura 1 - Acanthohoplites sp., molde natural em matriz silicificada, $\times 1$

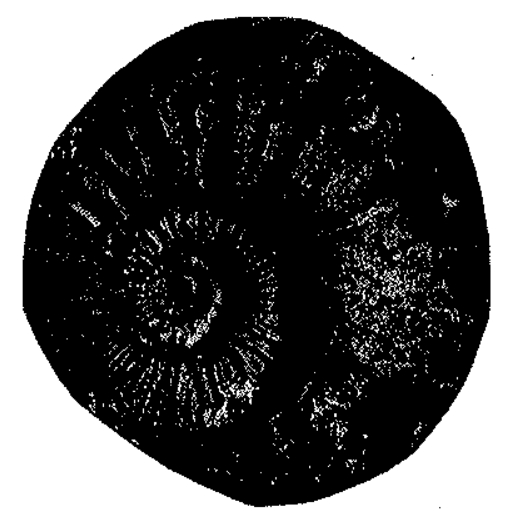

Figura 2 - Acanthohoplites sp., negativo do molde do exemplar da Fig. 1, obtido em Naftollex, $\times 1$ 
Como já foi dito, possuímos um único espécime, fragmentário, constituído de molde externo lateral direito. Diâmetro máximo do exemplar, $47 \mathrm{~mm}$. Diâmetro externo do umbílico, $20 \mathrm{~mm}$. Voltas com os flancos aproximadamente planos, inferidamente pouco mais altas que espessas. Ornamentação bem característica constituída de costelas radiais ligeiramente flexuosas. As principais são portadoras de tubérculos, os quais nas voltas externas se localizam nas proximidades das regiões umbilical e sifonal. Entre as costelas principais se intercalam irregularmente costelas secundárias. Ramificações das costelas pouco conspícuas no espécine em lide. Sutura não observada.

DISTRIBUIĢÕES GEOLÓGICA E GEOGRAFICA Cronologicamente conhecido do Aptiano Superior ao Albiano Inferior, o gênero é mencionado, entre outras regiões, do Arizona e Califórnia, nos EUA, do México, da Europa e do Japão. Desconhecemos referências anteriores de ocorrências do gênero no Brasil.

$$
\begin{aligned}
\text { Superfamília } & \text { Acanthocerataceae } \\
\text { Família } & \text { Lyelliceratidae } \\
\text { Gênero } & \text { Lyelliceras Spath, } 1921 \\
& \text { Lyelliceras sp. }
\end{aligned}
$$

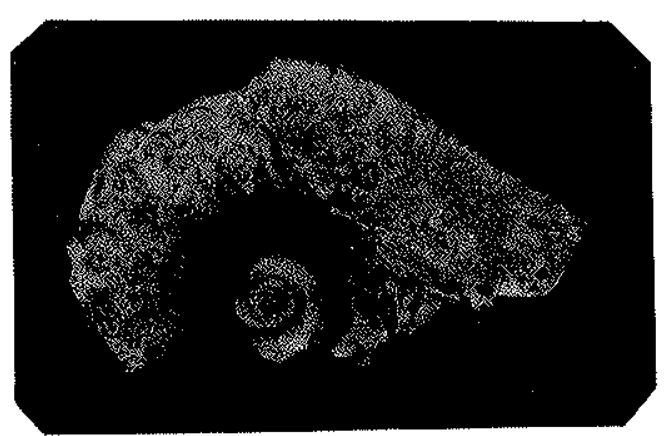

Figura 3 - Lyelliceras sp., molde natural, parcialmente recoberto por concha também silicificada, $\times 1$

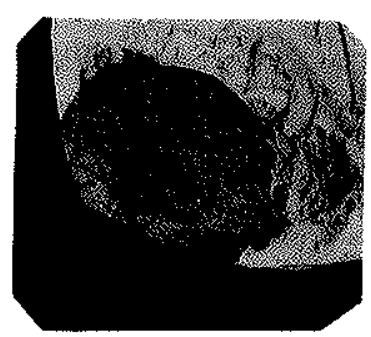

Figura 4 - Lyelliceras sp., negativo em gesso da porção (molde externo) do exemplar da Fig. 3, $\times 1$

Fragmento de concha moderadamente evoluta, exibindo pequena porção de molde interno, parcial e interruptamente recoberto pela delgada concha silicificada. Mensurações impossibilitadas pelo estado de preservação do espécime. Seção das voltas levemente comprimida lateralmente. Ornamentação típica, caracterizada por costelas radiáis pouco pronunciadas, porém portadoras de vigorosos tubérculos mais conspícuos nas voltas externas. Tais tubérculos se distribuem em duas filas situadas, uma na extremidade umbilical e outra na extremidade ventral dos flancos. Na região sifonal aparecem três filas de tubérculos sendo uma obviamente central. Sutura não observada.

DISTRIBUIÇÕES GEOLÓGICA E GEOGRÁFICA O gênero distribui-se do Albiano Inferior ao Albiano Médio, sendo mencionado entre outros, nos seguintes países: França, México, Colômbia e Peru. Mencionamos aqui, pela primeira vez, a ocorrência de tal gênero no Brasil.

Posição estratigráfica e correlação com os sedimentos de Sergipe Diversas colunas litoestratigráficas têm sido propostas para o Jurássico-Cretáceo da bacia Sergipe- 
-Alagoas, no que tange ao grupo inferiormente situado, ou seja, o Grupo Baixo São Francisco. Admitiremos aqui como hipótese de trabalho, as seqüências mencionadas por Mendes e Petri (1971), incluídas nesse Grupo, que são as seguintes:

\section{SERGIPE}

Formações

Riachuelo

Ibura

discordância

Morro do Chaves

discordância

Poxim

Feliz Deserto

Japoata

\section{ALAGOAS}

Formaģões

Maceió
Ibura
discordância
Jequiá
discordância
Poxim
Feliz Deserto (Inferiormente Purbeckiana)
Japoatã (Purbeckiana)

Como se sabe, dados gerais obtidos sobretudo por pólens, ostracodes, restos de plantas e de peixes permitem afirmar que todas as formações pré-Riachuelo na coluna de Sergipe e todas aquelas correspondentes a Alagoas foram depositadas em ambientes não-marinhos.

Os sedimentos de Tapera, em Alagoas, tendo em vista a distribuição geológica dos cefalópodes aqui referidos, devem corresponder ao Albiano Inferior. Isso nos permite, em primeira aproximação, correlacioná-los temporalmente com os da Formação Riachuelo.

CONCLUSÓES 1. A transgressão marinha aptiana e albiana, até esta data assinalada restritamente em Sergipe na bacia Sergipe-Alagoas, é aqui demonstrada por ter atingido terrenos bem mais ao norte. Caso seja descoberto um documentário mais bem preservado, pertencente à Formação Estivas ao sul do Recife e suposto ainda inexatamente Albiano, estará comprovada a continuidade dessa transgressão mesocretácea na atual região litorânea do nordeste até latitude um pouco ao sul do Recife. 2. Estudos mais detalhados, à base de maior documentário paleontológico, provavelmente estribados em microfósseis, permitirão confirmar ou não, de forma mais precisa, a idade ora proposta, bem como propiciar uma correlação bioestratigráfica com as camadas sergipanas. 3 . Os sedimentos silicificados, pela primeira vez aqui mencionados como ocorrendo na bacia Sergipe-Alagoas, devem corresponder, pela idade inferida e pelo caráter oolítico preservado em muitas amostras, à porção superior da Formação Riachuelo, ou seja, à facies Maruim, do graben de Sergipe.

\section{BIBLIOGRAFIA}

BEURLEN, K. - 1964 - Introduçåo à Estratigrafia Geral e Gomparada, 1.a ed., Expansåo Gráfica, Recife

BEURLEN, G. - 1968 - A fauna do complexo Riachuelo Maruim. I - Ammonoidea. Rio de Janeiro, Boletim Técnico da Petrobrás, 11 (4): 437-482

BRITO, I. M. e RODRIGUES, M. A. - 1967 - Contribuição ao Conhecimento dos Amonitas Albianos (Cretáceo) de Sergipe. Instituto de Geociências, Geologia. Bol. n. ${ }^{\circ}$ 1, pp. 53-69, Rio de Janeiro

CAROZZI, A. - 1953 - Petrographie des roches sédimentaires. F. Rouge \& Cie S.A. Librairie de L'Université, 250 pp., Lausanne

MAURY, G. J. - 1930 - O Cretáceo da Parahyba do Norte. Brasil, Departamento Nacional da Produção Mineral, Divisão de Geologia e Mineralogia, Monografia, 8, 308 pp., Rio de Janeiro 
MAURY, G. J. - 1936 - O Cretáceo de Sergipe. Brasil, Departamento Nacional da Produção Mineral, Divisão de Geologia e Mineralogia, Monografia, 11, 283 pp., Rio de Janeiro

MENDES, J. G. e PETRI, S. - 1971 - Geologia do Brasil. Instituto Nacional do Livro, Ministério da Educação e Cultura, 207 pp., Rio de Janeiro

MOORE, R. G. et al. -1957 - Treatise on invertebrate paleontology. Part I, Mollusca 4, Geological Society of America, New York

PETTIJOHN, F.J. - 1957 - Sedimentary Rocks, 2. ${ }^{\text {a }}$ ed., Harper \& Brothers, 708 pp., New York

ROMAN, F, - 1938 - Les Ammonites Jurassiques et Cretacées, 554 pp., 53 pls., 496 figs. Masson, Paris 